\title{
A Comparative Study of Hemodynamic Effects of Levosimendan and Milrinone in Patients Undergoing Off-Pump Coronary Artery Bypass Grafting
}

\author{
Chand Kishan Vyas ${ }^{1}$, Ramesh Kumar², Neelu Sharma ${ }^{3}$, Indu Verma', Anjum Saiyed ${ }^{1}$ \\ ${ }^{1}$ Professor, Department of Anesthesia, SMS Medical College, Jaipur, Rajasthan, India, ${ }^{2}$ Post Graduate Student, Department of Anesthesia, SMS Medical \\ College, Jaipur, Rajasthan, India, ${ }^{3}$ Assistant Professor, Department of Anesthesia, SMS Medical College, Jaipur, Rajasthan, India.
}

\section{Abstract}

Background: Off-Pump CABG or "beating heart" surgery possess a challenge to the anesthesiologist. Main goals are provision of safe anesthesia with maximum myocardial protection and maintenance of hemodynamics with various manipulation of heart during in order to visualize and graft the coronary arteries. Anesthetic regimen and ionotropic support influences postoperative myocardial function and outcome in coronary bypass surgery patients. Objective: To compare and assess haemodynamic effects of Levosimendan and Milrinone in patient undergoing off pump coronary artery bypass grafting with compromised cardiac function (NYHA III,IV) and pre-operative, left ventricular ejection fraction (LVEF) < 45\%. Subjects and Methods: Patients were randomly allocated to 2 groups (64 patients in each group). Levosimendan Group (Group A) received infusion of Inj. Levosimendan $0.1 \mu \mathrm{g} / \mathrm{kg} / \mathrm{min}$ after loading dose of $12 \mu \mathrm{g} / \mathrm{kg}$ over 10 mins. While Milrinone Group (Group B) received infusion of inj. Milrinone $0.5 \mu \mathrm{g} / \mathrm{kg} / \mathrm{min}$ after loading dose of $50 \mu \mathrm{g} / \mathrm{kg}$ over 10 mins. HR, MAP, CVP, CI, SVRI, lactate levels were monitored at baseline, after induction, after sternotomy, at 30mins ,thereafter 6, 12, and 24 hours using Flo-Trac sensor (Edwards Life sciences). Results: Heart Rate, CI was significantly higher in Levosimendan group while MAP, SVRI and lactate levels were lower in Levosimendan group as compared to Milrinone group. Need of other inotropic support is more in Milrinone group. Conclusion: Levosimendan maintained the haemodynamic parameters better as compared to Milrinone in off pump CABG patients with low preoperative ejection fraction and also better end organ perfusion represented by lower lactate levels.

Keywords: Off-pump CABG, Levosimendan, Milrinone, Hemodynamics.

Corresponding Author: Dr. Neelu Sharma, Assistant Professor, Department of Anesthesia, SMS Medical College, Jaipur, Rajasthan, India.

Received: February 2020

Accepted: February 2020

\section{Introduction}

Off- Pump coronary artery bypass graft surgery (OPCAB) is considered a safe alternative to conventional coronary artery bypass grafting with cardio-pulmonary bypass (CPB) for myocardial revascularization because it may be associated with decreased postoperative morbidity and reduced total costs. Avoiding CPB eliminates aortic cannulation and crossclamping and expected to reduce systemic inflammatory response, coagulation disorders and multiple organ dysfunction. $^{[1]}$ However, the haemodynamic instability associated with positioning and stabilizing the heart as well as the interruption of the coronary artery flow is an important factor limiting the performance of OPCAB. ${ }^{[2]}$

A combination of surgical manoeuvers help in preventing conduction and hemodynamic deterioration which might occur during the graft positioning on beating heart. These include trendelenburg position, fluid administration and use of vasopressors and inotropes if necessory. ${ }^{[3]}$ Inotropic agents enhance myocardial contractility at a cost of increase in myocardial oxygen consumption, ${ }^{[4]}$ which may further alter the already compromised myocardial oxygen balance in patients with preexisting ventricular dysfunction.

Levosimendan is one of a new class of inodilators which enhances myocardial contractility by sensitizing troponin $\mathrm{C}$ to calcium within cardiomyocytes. ${ }^{[5]}$ Levosimendan also has a vasodilating effect on systemic, coronary and pulmonary vasculature through activation of adenosine triphosphate sensitive potassium channels and phosphodiesterase inhibition. ${ }^{[6,7]}$ Milrinone is an inodilator which acts by inhibiting PDE III enzymes and acts independently of $\beta$ receptors. It lessens myocardial ischaemia and cell damage. ${ }^{[8]}$ Recently, a number of clinical studies have been carried out to evaluate the effects of Milrinone on cardiac function in patients with low ventricular ejection fraction undergoing CABG. However, it has been inconclusive because of the inconsistent results. In addition, some studies found that Milrinone increased the incidence of postoperative atrial arrhythmias and did not show any long-term beneficial effects on survival. While Levosimendan has also shown promise in elective therapy of cardiac surgical patients with high perioperative risk or compromised left ventricular function. 
With this background this study was conducted to assess the comparative hemodynamic effects of Levosimendan and Milrinone in patients undergoing off pump coronary artery bypass grafting.

\section{Subjects and Methods}

With due permission from institutional ethical committee, this Hospital based prospective randomized comparative study was conducted in Department of Anaesthesia, S.M.S. Medical College, Jaipur, Rajasthan. The study population consists of 64 patients in each group of any age of either sex with Patients with compromised cardiac function (NYHA III, IV) and Preoperatively LVEF < $45 \%$ by echo study undergoing off pump CABG. Exclusion criteria were symptomatic congestive heart failure $(\mathrm{CHF})$, pre-existing renal failure, liver and neurological disorder, preoperative cardiopulmonary resuscitation and preoperative use of Milrinone or Levosimendan or allergy to these drugs. All patients had a preanaesthetic checkup and consumed nothing by mouth 8 hours preoperatively. Patient's identity, consent and PAC were checked before taken on operation table. In operating room 18 gauge peripheral venous cannula was inserted into right antecubital vein and all routine monitors: 5-lead ECG Electrodes, NIBP cuff and Pulse oximeter were attached. All baseline parameters Blood Pressure (BP), Heart rate (HR), Mean arterial pressure (MAP), respiratory rate (RR), oxygen saturation (SPO2) were recorded.

Femoral artery cannulation was performed and Central venous catheter was inserted into Right Internal jugular vein under local anesthesia. Baseline data in the form of Heart rate (HR),Blood Pressure (B.P.), Mean arterial pressure (MAP), Central venous pressure (CVP), Cardiac index (CI), Systemic Vascular Resistance Index (SVRI), were recorded using FloTrac sensor (Edwards Life sciences). Base line ABG done to determine lactate level.

\section{Anesthetic Technique:}

All patients were given Inj. Midazolam $(0.15 \mathrm{mg} / \mathrm{kg})$ and Inj. Fentanyl $(3 \mu \mathrm{g} / \mathrm{kg})$ and pre oxygenated with $100 \%$ O2 for 5 minutes before induction. All patients were induced with inj. Etomidate $(0.3 \mathrm{mg} / \mathrm{kg})$ and inj. Rocuronium $(0.9 \mathrm{mg} / \mathrm{kg})$. Intubation was done with endotracheal tube of appropriate size after direct laryngoscopy. Patient was maintained with oxygen, inj. Vecuronium, inj. Midazolam and inj. Fentanyl. After intubation and securing the airway, patients were given loading dose of study drugs i.e. Levosimendon ( $12 \square \mathrm{g} / \mathrm{kg}$ over 10 minutes. diluted in $50 \mathrm{ml}$ dextrose $5 \%$ in infusion pump) in Group A and Milrinone (50 $\square \mathrm{g} / \mathrm{kg}$ over 10 minutes diluted in $50 \mathrm{ml}$ dextrose $5 \%$ in infusion pump.) in Group B. Surgery was started, group A continued infusion of Levosimendan $0.1 \mu \mathrm{g} / \mathrm{kg} / \mathrm{min}$ and group B continued Milrinone infusion $0.5 \mu \mathrm{g} / \mathrm{kg} / \mathrm{min}$ via infusion pump. The study drugs were diluted in such a way that equal infusion rates were achieved for comparable patients.

\section{Protocol for additional inotrope was-}

1. MAP $>50 \mathrm{mmHg}, \mathrm{CI}>1$ dyne-sec-m $2 / \mathrm{cm} 5$ - continue study drug

2. MAP $<50 \mathrm{mmHg}, \mathrm{CI}<1$ dyne-sec-m2/cm5, SVRI<1200unitsNoradrenaline $0.05 \mu \mathrm{g} / \mathrm{kg} / \mathrm{min}$.

3. MAP $<50 \mathrm{mmHg}, \mathrm{CI}<1$ dyne-sec-m2/cm5, SVRI $>1200$ unitsAdrenaline $0.05 \mu \mathrm{g} / \mathrm{kg} / \mathrm{min}$

Haemodynamic Variables: In both groups HR, MAP, CVP, CI, SVRI, lactate levels were monitored at baseline, after induction, sternotomy, at 30 mins and thereafter at 6, 12, and 24 hours after Surgery. Both study drugs and additional inotropes were tapered after patient was extubated and haemodynamically stable. Additional inotrope requirement intraoperatively and postoperatively, if any noted.

\section{Statistical Analysis}

The statistical analysis was carried out using Statistical Package for Social Sciences (SPSS Inc., Chicago, IL, version 20.0 for Windows). Parametric data were analyzed using unpaired t-test. Qualitative or categorical variables were compared using Chi square test.

\section{Results}

Both the groups were comparable in terms of demographic data i.e. age, sex and body surface area.

Table 1: Demographic variables.
\begin{tabular}{|l|l|l|l|}
\hline & Group A & Group B & P value \\
\hline Age (years) & $56.80 \pm 11.00$ & $56.34 \pm 10.74$ & 0.814 \\
\hline Sex & $7 / 57$ & $7 / 57$ & \\
\hline BSA (m2) & $1.47 \pm 0.118$ & $1.4 \pm 0.88$ & 0.210 \\
\hline
\end{tabular}

\begin{tabular}{|c|c|c|c|c|c|c|c|}
\hline Group A & $86.9 \pm 21.9$ & $90.5 \pm 18.4$ & $87.0 \pm 17.5$ & $100.01 \pm 8.1^{*}$ & $95.3 \pm 13.7^{*}$ & $88.8 \pm 11.2$ & $87.7 \pm 9.7$ \\
\hline \multicolumn{8}{|l|}{ MAP } \\
\hline Group A & $87.3 \pm 10.5$ & $81.6 \pm 12.4$ & $64.5 \pm 11.2$ & $71.2 \pm 12.6^{*}$ & $74.0 \pm 11.9^{*}$ & $71.2 \pm 12.6$ & $73.0 \pm 8.8^{*}$ \\
\hline Group B & $84.5 \pm 16.9$ & $80.5 \pm 15.9$ & $66.2 \pm 12.9$ & $79.8 \pm 10.2 *$ & $76.3 \pm 7.4^{*}$ & $79.8 \pm 10.2$ & $80.2 \pm 10.8^{*}$ \\
\hline \multicolumn{8}{|l|}{ CVP } \\
\hline \multicolumn{8}{|l|}{ CI } \\
\hline Group A & $4.1 \pm 1.7$ & $4.0 \pm 1.5$ & $3.3 \pm 1.0$ & $5.3 \pm 1.5$ & $4.4 \pm 1.3^{*}$ & $3.2 \pm 0.7$ & $3.9 \pm 0.8$ \\
\hline Group B & $3.6 \pm 1.1$ & $3.5 \pm 0.9$ & $4.1 \pm 2.1$ & $4.4 \pm 2.1$ & $3.4 \pm 0.7 *$ & $3.3 \pm 0.8$ & $3.7 \pm 0.8$ \\
\hline \multicolumn{8}{|l|}{ SVRI } \\
\hline Group A & $1715 \pm 624$ & $1617 \pm 665$ & $1413 \pm 454$ & $1136 \pm 330$ & $1361 \pm 458^{*}$ & $1732 \pm 527$ & $1423 \pm 308^{*}$ \\
\hline Group B & $1818 \pm 535$ & $1775 \pm 467$ & $1244 \pm 473$ & $1359 \pm 451$ & $1756 \pm 365^{*}$ & $1852 \pm 374$ & $1681 \pm 387^{*}$ \\
\hline
\end{tabular}




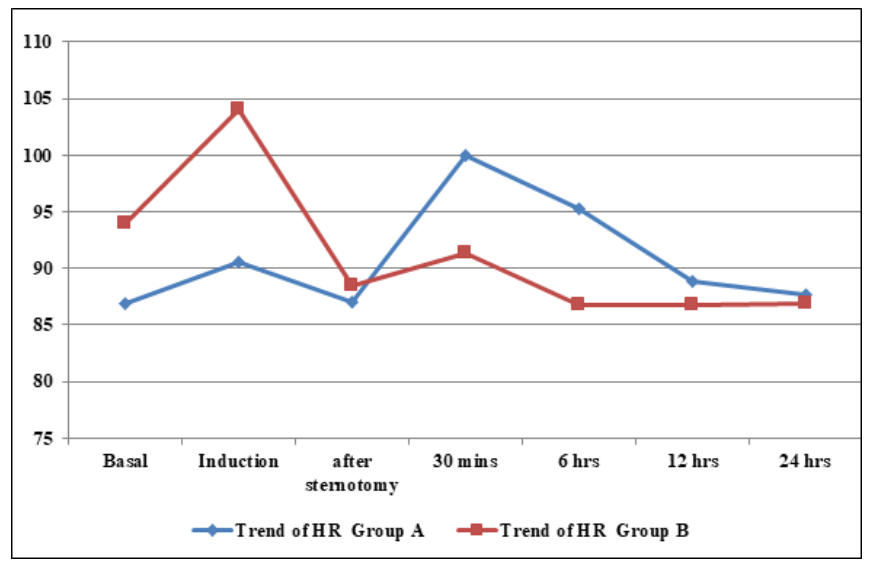

Figure 1: Heart rate at various time intervals in both groups

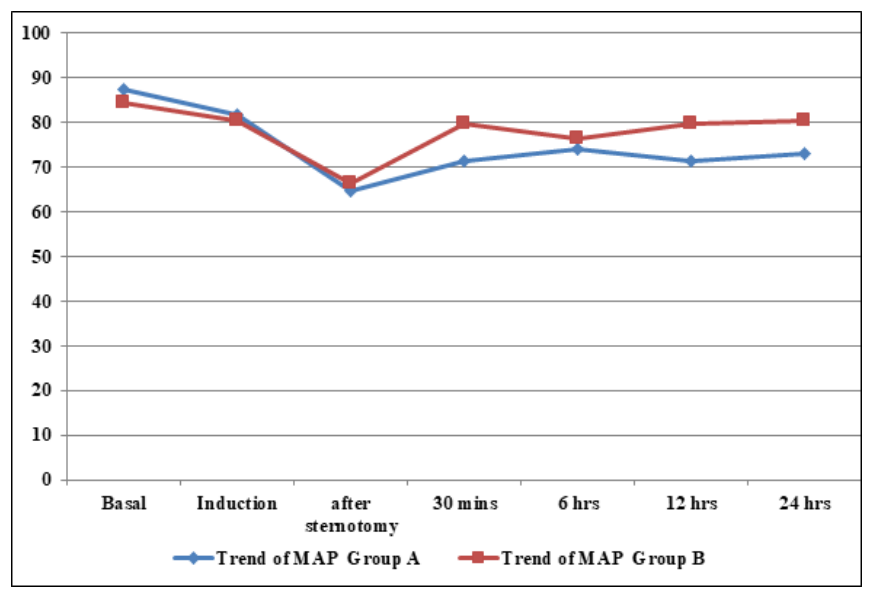

Figure 2: MAP trends in both groups at various time intervals

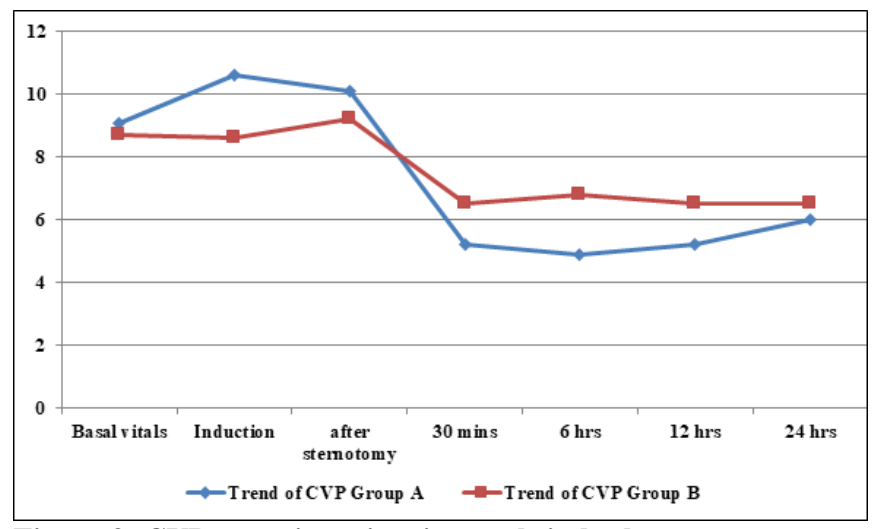

Figure 3: CVP at various time intervals in both groups

[Table 2] showed compared different hemodynamic parameters at various time intervals in both groups. Heart Rate was significantly higher in Levosimendan group at 30 minutes $(100.01 \pm 8.1$ vs $91.3 \pm 13.3)$ and 6 hours $(95.3 \pm 13.7$ vs $86.8 \pm 8.6$ ) [Figure 1]. CI was significantly higher in Levosimendan group at 6 hours $(4.4 \pm 1.3$ vs3.4 \pm 0.7$)$ [Figure 4] while MAP were lower in Levosimendan group as compared to Milrinone group at 30 minutes $(71.2 \pm 12.6$ vs $79.8 \pm 10.2)$, 6 hour $(74.0 \pm 11.9$ vs $76.3 \pm 7.4)$ and 24 hours (73.0 \pm 8.8 vs $80.2 \pm 10.8)$ [Figure 2] .SVRI was also lower in Levosimendan group as compared to Milrinone group at 6 hour $(1361 \pm 458$ vs $1756 \pm 365)$ and 24 hour $(1423 \pm 308$ vs1681 \pm 387 ) [Figure 5]. Lactate levels were lower in Levosimendan group as compared to Milrinone group.
[Table 3]

33 out of $64(51.5 \%)$ patients required additional inotrope (15 adrenaline, 18 noradrenaline) in Group A compared to 42 (65.6\%) out of 64 patients (20 adrenaline, 22 noradrenaline) in Group B.( p value <0.05)

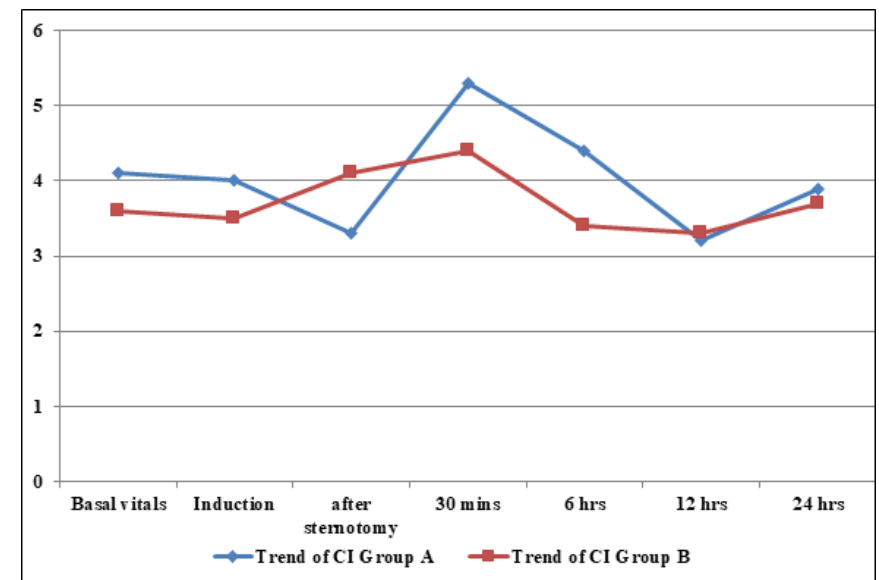

Figure 4: Cardiac Index (CI) at various time intervals in both groups

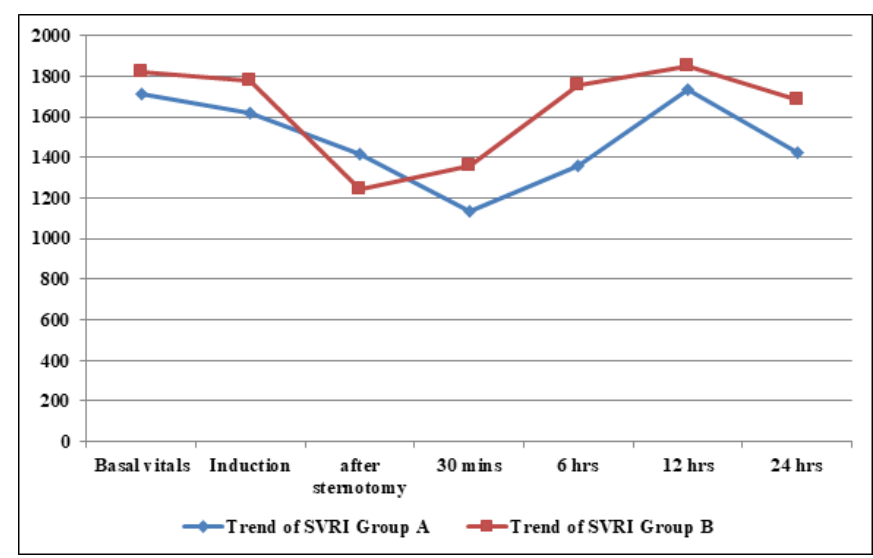

Figure 5: SVRI: trends at various time intervals in both groups

\begin{tabular}{l}
\hline Table 3: Trend of Lactate levels (mmol / I) \\
\begin{tabular}{|l|l|l|l|}
\hline & Group A & \multicolumn{1}{c|}{ Group B } & p Value \\
\hline Basal & $1.0 \pm 0.5$ & $1.3 \pm 0.6$ & 0.0510 \\
\hline Induction & $1.0 \pm 0.5$ & $1.4 \pm 0.6$ & 0.0410 \\
\hline After sternotomy & $2.4 \pm 1.2$ & $4.2 \pm 1.3$ & $0.0001^{*}$ \\
\hline $30 \mathrm{mins}$ & $2.39 \pm 1.1$ & $2.42 \pm 0.7$ & 0.9200 \\
\hline $6 \mathrm{hrs}$ & $2.5 \pm 0.8$ & $4.1 \pm 0.9$ & $0.0001^{*}$ \\
\hline $12 \mathrm{hrs}$ & $3.3 \pm 1.0$ & $3.4 \pm 1.0$ & 0.8300 \\
\hline $24 \mathrm{hrs}$ & $2.39 \pm 1.1$ & $2.42 \pm 0.7$ & 0.9200 \\
\hline
\end{tabular}
\end{tabular}

\section{Discussion}

$\mathrm{OPCAB}$ is an attractive alternative to on-pump surgery, especially for patients with altered cardiac function and severe comorbidities, including old age and coagulation disorders.1 However, the haemodynamic instability associated with positioning and stabilizing the heart as well as the interruption of the coronary artery flow is an important factor limiting the performance of OPCAB. Numerous studies regarding the changes in haemodynamics and its management have been performed. ${ }^{[9-11]}$ The primary goals of anaesthetic management are maintenance of adequate haemodynamics during heart 
enucleation and optimal myocardial protection during ischaemic events. Prophylactic usage of inotropic agents seems to be reasonable in this setting for patients undergoing OPCABG with normal left ventricular (LV) function. ${ }^{[12,13]}$ The presence of severe Left Ventricular dysfunction is an additional risk for $\mathrm{CABG}$.

Presently, there is still no consensus on vasoactive medications use during the OPCABG surgery. $\beta$-adrenoceptor agonists could impair myocardial function by increasing oxygen consumption, and their positive chronotropic effect can make surgeon's job more difficult. In patients who received arterial grafts, alternative use of vasoconstrictors can produce vasospasm and lead to dramatic hemodynamic deterioration. $^{[13,14]}$ Furthermore, vasoconstrictors can additionally decrease cardiac index as they increase afterload. ${ }^{[13,14]}$ Because of the unfortunate effects of the previously mentioned vasoconstrictors and $\beta$ adrenoceptor agonists, another options are drugs of class of inodilators. Milrinone and Levosimendan, by different mechanism, enhance the contractility of myocardium, along with vasodilatation hence improving cardiac output in patients with poor left ventricular function. Levosimendan a "myofilament Ca2+ sensitizer" enhances cardiac contractility, has no negative impact on diastolic function and neutral effect on heart rhythm. ${ }^{[15,16]}$ Milrinone a bipyridine inhibits the low Km.,CGMP-inhibited phosphodiesterase in myocardium producing inotropic effect and vasodilation but not shown to increase myocardial oxygen consumption. ${ }^{[16,17]}$

To compare both the drugs in terms of hemodynamic profile, the present study was conducted in the Department of Anaesthesiology, S.M.S. Medical College and Attached Group of Hospitals, Jaipur. 128 patients were randomly allocated in two groups, 64 patients in Group A (Levosimendan group) and 64 patients in Group B (Milrinone group). There was no statistically significant difference between the two groups with regard to demographic data (i.e. Sex, Age, BSA, (p value >0.05).

Our study showed no significant difference in Heart Rate between both groups except at 30 minutes and 6 hours, when Heart Rate was significantly higher in Levosimendan group. Kivicco et al, ${ }^{[18]}$ conclude that Levosimendan produces dose dependent increase in cardiac output stroke volume and heart rate. While Milrinone can increase heart rate but that is not a consistent response and bradycardia can occur. ${ }^{[19]}$ Studies show different effect of milrinone on heart rate individually and also in comparison to Dobutamine and Levosimendan. Study done by Mishra et al on patients with valvular disease and concomitant pulmonary artery hypertension also showed higher heart rate in Levosimendan group. The heart rates were significantly higher at 30 minutes post-CPB (p 0.016) and 1 hour(p 0.003), 6 hours (p 0.015) and 24 hours (p0.011) post ICU admission in the Levosimendan group than in the Milrinone group. ${ }^{[20]}$ Study done by Jana et al8 and Sunny et al, ${ }^{[21]}$ showed no difference between levosimendan and milrinone group. ${ }^{[8]}$

Our study showed no significance difference in CVP between both groups similar to Jana et al and Sunny et al. ${ }^{[8,21]}$

When compared in terms of MAP, MAP was significantly lower in Group A compared to Group B at 30 mins ( $\mathrm{p}$ value= $0.0210), 12 \mathrm{hrs}(\mathrm{p}$ value $=0.0210)$ and $24 \mathrm{hrs}$ ( $\mathrm{p}$ value $=$ 0.0280). Our study also showed a decrease in the SVRI at 6 hours and 24 hours in levosimendan group than Milrinone group which was consistent with Mishra et al20 and Saad G et al, ${ }^{[22]}$ which showed decrease in SVR from baseline in both Levosimendan group and Milrinone group but on comparison Levosimendan showed statistically more significant decrease in SVR as compared to milrinone. This shows high degree of vasodilatation with use of levosimendan by opening ATP sensitive potassium channels in smooth muscle cells. ${ }^{[18,23]}$ Gandham $\mathrm{R}$ et al also showed greater degree of vasodilation with Levosimendan. ${ }^{[2]}$ Decreased MAP, SVR and SVRI reflects a decrease in left ventricular after load and preload, increased coronary blood flow and a resultant "anti-ischemic" effect.

Cardiac index was significantly higher in levosimendan group in our study at 6 hours in comparison to Milrinone group. The increase in cardiac index is attributed to increase in stroke volume beneficial for patient with low ejection fraction. Mishra et al, ${ }^{[20]}$ also observed increased cardiac index in Levosimendan group where at 6 hours left ventricular ejection fraction improved. Saad $\mathrm{G}$ et al, ${ }^{[22]}$ observed that C.O. was improved from baseline after giving Levosimendan and Milrinone both but comparative statistical analysis showed that levosimendan improved cardiac output more in comparison to milrinone. Tritapepe et al found significant post-operative increase in CI indicating increased myocardial contractility. ${ }^{[25]}$ Shawaf et al, ${ }^{[26]}$ found Levosimendan to be superior to Milrinone in increasing cardiac output in diabetic patients with low ejection fraction undergoing elective coronary artery surgery. Lechner et al, ${ }^{[27]}$ showed a similar increase in cardiac index with either levosimendan or milrinone during neonatal and infant cardiac surgery. In the decompensated low output patients. Levosimendan has the upper hand over the other inotropic drugs, which include prolonged drug effect after single infusion, without any arrhythmias and absence of drug induced myocardial ischemia. Levosimendan improves cardiac performance in Left ventricular failure patients from acute coronary artery syndromes. ${ }^{[23]}$

De Hert et al have shown that Levosimendan in combination with dobutamine maintained stroke volume better than other inodilator milrinone in combination with dobutamine in cardiac surgery patients with preoperative ejection fraction $<30 \%$, also consistent with our results. ${ }^{[27]}$

In our study, 33 out of 64 patients $(51.5 \%)$ required inotropic support in Group A while 42 out of 64 patients $(65.6 \%)$ required ionotropic support in group B. This shows lesser inotrpic support required in Levosimendan group in comparison to Milrinone group. This results was consistent with study done by Jana et al8 and Chang et al. ${ }^{[29]}$ Study by Saad G et al, ${ }^{[22]}$ showed greater requirement of inotropic support in milrinone group results coinciding with our study, hence prove that Levosimendan allows the avoidance of high doses of conventional inotropes which are implicated in consequences and complications in accordance to the exaggerated effects of vasoconstriction.

Lactate levels were lower in Levosimendan group compared to Milrinone group. This effect may be related to direct organo-protective actions of the drugs or are the consequences of the better postoperative cardiac function, resulting in improved early organ perfusion. Milrinone enhanced myocardial contractility but at the cost of increased 
myocardial oxygen demand with a consequent risk of ischemia and arrhythmia. In contrast Levosimendan improves cardiac muscle contractile force, vascular smooth muscle relaxation, coronary blood flow and $\mathrm{CO}$ without increasing oxygen consumption of the heart muscles. ${ }^{[23]}$ Further by opening the KATP channel located at the level of mitochondria, it preserves cellular energy homeostasis and protect mitochondrial oxidative stress. This recovery of aerobic metabolism is reflected by lower lactate levels and reduced lactate / pyruvate ratio. ${ }^{[30]}$ Fang et al studied effect of levosimendan on hemodynanamics and cardiac function in patients with septic shock with low EF $(<45 \%)$ and observed decrease in lactate level. ${ }^{[31]}$ Alhashemi also treated cardiogenic shock with levosimendan and found decrease in serum lactate level. ${ }^{[32]}$ Same observations were seen in metaanalysis by Chang et al that lactate levels were profoundly reduced in sepsis patients. ${ }^{[28]}$ Amiet et al also studied Levosimendan in pediatric patients and observed lower lactate levels. ${ }^{[33]}$ Study by Matthias et al (55) also showed better metabolic effects of milrinone in comparison to adrenaline in term of lower lactate level in plasma. ${ }^{[34]}$ Tatlis et al also suggested that Milrinone has a beneficiary effect on aerobic tissue metabolism after extracorporeal circulation reflected on serum lactate, possibly due to a combination of positive inotropic and peripheral vasodilatory effect of the drug. ${ }^{[35]}$ But due to paucity of literature on comparative difference in lactate level after giving both drugs, we recommend further studies.

\section{Limitations}

Left ventricular function of the heart was not assessed intraoperatively because of unavailability of TEE and PA pressure was not measured. Levels of CK-MB and Troponin I levels would be more helpful to assess prophylaxis against myocardial injury.

\section{Conclusion}

Our study conclude that as compared to Milrinone, Levosimendan maintained the haemodynamic parameters better in cardiac surgery patients with low preoperative ejection fraction and also better end organ perfusion represented by lower lactate levels.

\section{References}

1. Chassot P, Van der Linden, Zaugg M., MuellerX. M, Spahn M et al. Offpump coronary artery bypass surgery: Physiology and anaesthetic management. Br J Anaesth 2004; 92: 400 -13

2. KwakYL, Oh Y.J., Jung SM et al. Change in right ventricular function during off pump coronary artery bypass graft surgery, European Journal of Cardio-thoracic Surgery 2004 April;25(4): 572-7.

3. Chooriyil N, Palappallil DS. Perioperative inotrope use in off pump coronary artery bypass graft surgeries: Journal of Clinical Diagnosis and Research.2017 dec;11(2):PC16-19.

4. Shah B, Sharma P, Brahmabhatt A et al. Study of Levosimendan during off-pump coronary artery bypass grafting in patients with LV dysfunction:Indian Journal of Pharmacology 2014 jan-feb;46(1):29-34.

5. Sorsa T, Pollesello P, Rosevear P R et al. Stereo- selective binding of levosimendan to cardiac troponin $\mathrm{C}$ causes $\mathrm{Ca} 2+$-sensitization:.Eur $\mathrm{J}$ Pharmacol 2004; 486(1):1-8

6. Michaels A D, McKeown B, Kostal M et al. Effects of intravenous levosimendan on human coronary vasomotor regulation, left ventricular wall stress and myocardial oxygen uptake: Circulation 111:15041509,2005 .

7. Edes I, Kiss E, Kitada Y et al. Effects of levosimendan, a cardiotonic agent targeted to troponin $\mathrm{C}$, on cardiac function and on phosphorylation and $\mathrm{Ca} 2+$ sensitivity of cardiac myofibrils and sarcoplasmic reticulum in guinea pig heart: Circ Res77:107-113, 1995

8. Jana T, Nayak K, Biswal P. Outcome of Prophylactic Use of Levosimendan and Milrinone in Open Heart Surgery With Compromised Ventricular Function - A Comparative Study Annals of International Medical and Dental Research: 2016; 2 (6).

9. Nierich A P, Diephuis J, Jansen EWL, Borst C, Knape J T; Heart displacement during off-pump CABG: how well is it tolerated?: Ann Thorac Surg 2000;70:466-72

10. Grundeman P F, BorstC, Van Herwaarden J A, Beck HJM, Jansen EWL. Hemodynamic changes during displacement of the beating heart by the Utrecht octopus method. Ann Thorac Surg 1997;63:S88-S92.

11. Do QB, Goyer C, Chavanon O, Couture P, Denault A, Cartier R.; Hemodynamic changes during off-pump CABG surgery. Eur J Cardiothorac Surg 2002;21:385

12. Kwak YL, Oh YJ, Shinn HK, Yoo KJ, Kim SH, Hong YW. Haemodynamic effects of a milrinone infusion without a bolus in patients undergoing off-pump coronary artery bypass graft surgery. Anaesthesia. 2004;59:324-31

13. Kim JH, Ham BM, Kim YL, Bahk JH, Ryu HG, Jeon YS et al. Prophylactic milrinone during OPCAB of posterior vessels: implication in angina patients taking betablockers: Eur J Cardiothorac Surg. 2003;24:770-6

14. Kerendi F, Halkos ME, Corvera JS, Kin H, Zhao ZQ, Mosunjac M, et al. Inhibition of myosin light chain kinase provides prolonged attenuation of radial artery vasospasm: Eur J Cardiothorac Surg. 2004;26:1149-55.

15. Sonntag S, Sundberg S, Lehtonen LA, Kleber FX. The calcium sensitizer levosimendan improves the function of stunned myocardium after percutaneous transluminal coronary angioplasty in acute myocardial ischemia: J Am Coll Cardiol;43:2177-82

16. Lilleberg J, Nieminen MS, Akkila J, Hasenfuss G et al. Effect of a new calcium sensitizer, levosimendan on hemodynamics, coronary blood flow and myocardial substrate utilization early after coronary artery bypass grafting ,Eur Heart J;19:660-668

17. Fredric Ginsberg and Joseph E. Parrilo. Sever Heart Failure: Critical Care Mediine (third edition) 2008,pages 559-87.

18. Kivikko M, Lehtonen L. Levosimendan a new inodilatory drug for the treatment of decompensated heart failure. Curr Pharm Des 2005;11(4):435-55.

19. Zimmerman J, Cahalan M. Pharmacology and physiology of anesthesia Elsevier (second edition), 2019

20. Mishra A, Kumar B, DuttaV, Mishra A K. Comparative effect of Levosimendan and Milrinone in cardiac surgery patients with pulmonary Hypertension and left ventricular dysfunction. 2016; 30(3);639-46.

21. Sunny, Yunus M, Karim HMR, Saikia M K, Bhattacharya P, Dey S. Comparison of Levosimendan ,Milrinone and Dobutamine in treating low cardiac output syndrome following bypass: J Clin Diagn Res 2016; 10(12):UC05-UC08.

22. Saad GT, Fawzy MF. Evaluating the Prophylactic use of Levosimendan Versus Milrinone in Open Heart Surgery Patients with Myocardial disfunction 1:218.doi:10.4172/scientificreports.218.

23. Gustaffson F, Guarracino F, Schwinger Robert H.G. The inodilator levosimendan as a treatment for acute heart failure in various settings: European journal supplement, vol 19,issue suppl_Cmarch 2017.

24. Gandham R, Syamasundar A, Ravulapalli H, et al. A comparison of hemodynamic effects of levosimendan and dobutamine in patients undergoing mitral valve repair/replacement for severe mitral stenosi: Ann Card Anaesth 16:11-15, 2013

25. Tritapepe L, De Santis, Vitale D, Guarracino F, Pellegrini F, Pietropaoli $\mathrm{P}$ et al. Levosimendan pre-treatment improves outcomes in patients undergoing coronary artery bypass graft surgery. British Journal of Anaesthesia. 2009;102 (2):198-204

26. Ai-Shawaf E, Ayed A, Vislocky I et al. Levosimendan or milrinone in type 2 diabetic patient with low ejection fraction under- going elective coronary artery surgery. J Cardiothorac Vasc Anesth 20: 353-57, 2006.

27. De Hert SG, Lorsomradee S, Cromheecke S, Van der Linden P et al. The effects of Levosimendan in cardiac surgery patients with poor left ventricular function: Anesth analg 2007;104:766-73

28. Lechner E, Hofer A, Leitner-Peneder G, et al. Levosimendan versus milrinone in neonates and infants after corrective open-heart surgery: A pilot study. Pediatr Crit Care Med 13:542-548, 2012.

29. Chang W, Xie JF, XU J-Y, Yang Y. Effects of levosimendan on mortality 
in severe sepsis and septic shock: A meta-metalysis of randomized trials: BMJ Open 2018 mar 30;8(3).

30. Raja SG, Rayen BS. Levosimendan in cardiac surgery: current best available evidence: Ann Thoracic Surg 2006; 81:1536-46.

31. Fang M, Dong S. Effects of levosimendan on hemodynamics and cardiac function in patients with septic shock: Zhonghua Wei Zhong Bing Jiu Yi Xue; 2014 oct; 26(10):692-6.

32. Alhashemi J.A. Treatment of cardiogenic shock with levosimendan in combination with b-adrenargic antagonist: Br J Anaesth 2005:95: 648-50.

33. Amiet V, Perez M-H, Longchamp D, Ksontini T, Natterer J, Worthrich
SP, Cotting J, Bernardo SD. Use of Levosimendan in postoperative setting after surgical repair of congenital heart disease in children: pediatr cardiol Jan 2018,39 (1),19-25.

34. Matthias H, Mariat W, Julia G, Stephan K, Hermann H, Matthias B et al. The metabolic and renal effects of adrenaline and milrinone in patients with myocardial dysfunction after coronary artery bypass grafting: Critical care 2007; 11: R51.

35. Tatlis A, Papakonstantinou C, Tombouras $\mathrm{M}$ et al. the effect of milrinone on metabolism after cardiopulmonary bypass: J Cardiovasc Surg. 2008 feb;49(1):113-8.

Copyright: (C) the author(s), 2020. It is an open-access article distributed under the terms of the Creative Commons Attribution License (CC BY 4.0), which permits authors to retain ownership of the copyright for their content, and allow anyone to download, reuse, reprint, modify, distribute and/or copy the content as long as the original authors and source are cited.

How to cite this article: Vyas CK, Kumar R, Sharma N, Verma I, Saiyed A. A Comparative Study of Hemodynamic Effects of Levosimendan and Milrinone in Patients Undergoing Off-Pump Coronary Artery Bypass Grafting. Acad. Anesthesiol. Int. 2020;5(1):131-136.

DOI: dx.doi.org/10.21276/aan.2020.5.1.26

Source of Support: Nil, Conflict of Interest: None declared. 